\section{Diagnostic value of D-dimer's serum level in Iranian patients with cerebral venous thrombosis}

\author{
Leila Hashami, ${ }^{1}$ Vahid Rakhshan, ${ }^{2}$ \\ Hoda Karimian, 3 Mehdi Moghaddasi ${ }^{1}$ \\ 1Department of Neurology, Rasool Akram \\ Hospital, Iran University of Medical \\ Sciences, Tehran; 2Department of Dental \\ Anatomy and Morphology, Dental \\ Branch, Islamic Azad University, Tehran; \\ 3Department of Emergency Medicine, \\ Iran University of Medical Sciences, \\ Tehran, Iran
}

\section{Abstract}

Cerebral venous thrombosis (CVT) is a longterm debilitating vascular brain disease with high morbidity and mortality. It may be associated with rise in D-dimer level. The aim of this study was to examine this potential association and identify the critical D-dimer cut-off level corresponding to increase the risk of CVT. This case-control study was conducted on two groups of patients with and without CVT attending the Rasool Akram Hospital (Iran) during 2014 and 2015. D-dimer levels were measured by the rapid sensitive D-dimer assay. Data were analyzed by Spearman's correlation coefficient test, independent-samples t-test, backward-selection multiple linear regression and multiple binary logistic regression analyses. Sensitivity-specificity tests were used to detect D-dimer cut-off for CVT. Differences between the D-dimer levels of the case and control groups were significant $(\mathrm{P}<0.001)$. It showed that each level of increase in the number of symptoms could increase the risk of thrombosis occurrence for about 3.5 times. All symptom types except for headache were associated with D-dimer level, while headache has negative association with D-dimer level. D-dimer cut-off point for CVT diagnosis was estimated at $350 \mathrm{ng} / \mathrm{mg}$. We concluded that D-dimer serum level significantly rises in CVT patients. A rounded cut-off point of $350 \mathrm{ng} / \mathrm{mg}$ can be used as a diagnostic criterion for CVT prediction.

\section{Introduction}

For a long time cerebral venous thrombosis (CVT) was known as a rare long-term debilitating vascular brain disease of high morbidity and mortality. This disorder presents itself with a wide range of clinical signs and symptoms, like headache, cerebral hemorrhage and cerebral edema. ${ }^{1}$ Among its diagnostic challenges in the emergency department are its non-specific signs and symptoms. ${ }^{2}$ In recent years, the introduction of highly sensitive but non-invasive techniques such as magnetic resonance imaging (MRI), magnetic resonance venography, and computed tomography venography have led to the discovery of more cases. ${ }^{3,4}$ However, the difficulties associated with the use of these techniques have hindered their application as general screening methods for CVT. ${ }^{5}$ Hence, a simple, accessible and accurate method has always been of interest to neurology researchers.

D-dimer is a fibrin degradation product, the serum level of which begins to rise shortly after thrombus formation and the process of clot lysis. ${ }^{6}$ The measurement of serum Ddimer levels is nowadays used as a diagnostic method for non-CVT.7 Although D-dimer has a similar role in the diagnostic approach toward Deep Venous Thrombosis (DVT) and pulmonary thromboembolism it lacks a valid score for CVT diagnosis. Thus the role of D-dimer is still a matter of debate in the diagnostic approach toward suspected cases of CVT. ${ }^{8}$

One of the most recent statements released by the American Heart Association and American Stroke Association recommended the use of D-dimer as a useful indicator in the detection of suspected cases of CVT. ${ }^{9}$ Elsewhere, D-dimer evaluation yielded positive results in most but not all cases of CVT.10 However, sufficient research has not been conducted on the sensitivity and specificity of Ddimer in the diagnosis of CVT. Moreover, a conclusive D-dimer cut-off point has not been determined for CVT risk estimation for various ethnicities such as eastern ones. Considering the significance of timely diagnosis of CVT and the uncertainty surrounding the use of Ddimer in its diagnosis, we conducted this study to determine the serum levels of D-dimer in suspected patients attending Rasool Akram Hospital and in an Iranian population.

\section{Materials and Methods}

This case-control study was performed on all the available records of patients attending the Rasool Akram Hospital during 2014 and 2015. The ethics were approved by the Research Committee of Iran University of Medical Sciences, in accordance with the Helsinki declaration.

This study was conducted on two groups of patients with and without CVT. All patients attending Rasool Akram Hospital during 20152016 with adequate neuroimaging (MRI) data were originally evaluated to diagnose CVT
Correspondence: Mehdi Moghaddasi, Department of Neurology, Rasool Akram Hospital, Iran University of Medical Sciences, Tehran, Iran. Tel.: +98.21.64352496 - Fax: +98.21 .66517118 .

E-mail: moghaddasim@hotmail.com

Key words: D-dimer; venous thrombosis; cut-off value.

Contributions: the authors contributed equally.

Conflict of interest: the authors declare no possible conflict of interest.

Received for publication: 16 November 2015

Revision received: 7 January 2016.

Accepted for publication: 28 March 2016

This work is licensed under a Creative Commons Attribution NonCommercial 4.0 License (CC BYNC 4.0).

CCopyright L. Hashami et al., 2016

Licensee PAGEPress, Italy

Neurology International 2016; 8:6310

doi:10.4081/ni.2016.6310

according to classical neuroimaging signs. They were divided into two groups of patients with CVT (cases) and without CVT (controls). The sample size was determined based on a pilot study, which included a minimum of 90 patients in both groups (30 cases and 60 controls). The following data were gathered from all the participants: age, gender, weight, height, body mass index, cigarette smoking status, pregnancy, menopause status in women, intake of oral contraceptive pills (OCPs) in women, and their dosage if taken.

The participants' clinical signs and symptoms were assessed as well: isolated headache; headache and papilledema; and encephalic signs (seizure, focal weakness, consciousness, etc.). Relevant CVT risk factors [pregnancy, menopause status, OCPs use, factor V Leiden, Body Mass Index (BMI), smoking] were assessed and identified. Before starting any treatment or medications, including anticoagulant drugs in the case group, all the participants had blood tests conducted. Their Ddimer levels were measured by the rapid sensitive D-dimer assay and the results were reported.

\section{Statistical analysis}

Data were analyzed in the SPSS program (IBM Corp. Released 2011. IBM SPSS Statistics for Windows, Version 20.0. Armonk, NY, USA). Descriptive statistics (mean and median) were calculated for both groups. Associations between variables were assessed using Spearman's correlation coefficient, independent-samples t-test, backward-selection multiple linear regression, and multiple binary logistic regression analyses. The critical D- 
dimer level was estimated by sensitivity analysis. The level of significance was predetermined as 0.05 .

\section{Results}

In the case group there were 16 males and 13 females, with a mean age of $41.0 \pm 15.0$ years $(36.3 \pm 13.4$ in females; $44.8 \pm 15.6$ in males). In order to the site of thrombosis, there was 17 cases of transverse sinus (58\%), 9 in sagittal sinus (31\%), 2 in vein of Galen (6.9\%) and one in vein of Labbe (3.5\%). In the control group (patients clear of thrombosis diagnosis), there were 35 males and 24 females, with a mean age of $42.2 \pm 13.8$ years $(39.4 \pm 11.3$ in females; $44.0 \pm 45.2$ in males).

The mean D-dimer level in the case group was $2450.6 \pm 753.5 \mathrm{ng} / \mathrm{mg}$ (range: 135 to 3459 ), $2268.8 \pm 861.5 \mathrm{ng} / \mathrm{mg}$, and $2598.4 \pm 643 \mathrm{ng} / \mathrm{mg}$, respectively in 29 patients, 13 females and 16 males. There was only one patient with a DDimer level of $135 \mathrm{ng} / \mathrm{mg}$, and the rest of cases had D-Dimer levels above $1000 \mathrm{ng} / \mathrm{mg}$. None of the females was smokers, while 5 males $(31.3 \%)$ were smokers. Of the female cases, only $3(23.1 \%)$ were taking 0CPs. Of them, 1 (7.7\%) was pregnant, 2 others (15.4\%) were in their first or second postpartum weeks, and 3 (23.1\%) were menopausal. The mean BMI was $5.2 \pm 2.6 \mathrm{~kg} / \mathrm{m}^{2}(25.4 \pm 2.4$ in females; $25.1 \pm 2.8$ in males). The factor $\mathrm{V}$ Leiden was positive in 1 woman (7.7\%) and 3 men (18.8\%). Of the 29 cases, $55.2 \%, 41.4 \%$, and $3.4 \%$ had respectively 1,2 , and 3 symptoms. Headache, hemiparesis, and seizure were reported by $48.3 \%, 27.6 \%$, and $58.6 \%$ of the cases, respectively. Other symptoms (confusion, visual problems, ataxia, etc.) were reported by $10.3 \%$ of the cases. In the control group, D-dimer levels were $27.7 \pm 7.2$ (range: 12 to 43 ), $29.8 \pm 6.6$, and $26.3 \pm 7.3$, respectively in the controls i.e. 24 females, and 35 males. Twelve males (34.3\%) were smokers. There were no female smokers. Of the female controls, only 1 (4.2\%) was pregnant. The mean BMI of control group was $24.7 \pm 2.0 \mathrm{ng} / \mathrm{mg}(24.9 \pm 1.8$ in females; $24.6 \pm 2.1$ in males). Among the 59 controls, $79.7 \%$ and $20.3 \%$ had respectively 1 and 2 symptoms (i.e., only headache and seizure). Headache, hemiparesis, and seizure were reported by $100 \%$, $0.0 \%$, and $20.3 \%$ of the controls, respectively. Other symptoms (confusion, visual problems, ataxia, etc.) were not reported by any of the control group participants.

\section{Subgroup analyses \\ Case (cerebral venous thrombosis- positive)}

The backward-selection multiple linear regression on the case group data $(n=29)$ showed that of all the above mentioned variables (excluding symptom types), only age (beta $=0.472 ; \mathrm{P}=0.015$ ) significantly predicted D-dimer levels (all other variables were insignificant). According to the analyses performed on the case group data $(n=29)$, among the symptoms, headache (beta=-0.438; $\mathrm{P}=0.011$ ) negatively predicted $\mathrm{D}$-dimer levels. The symptoms hemiparesis, and seizure were not associated with D-dimer levels. However, other symptoms (confusion, ataxia, visual problems) were collectively associated with D-dimer levels (beta=0.352; $\mathrm{P}=0.036$ ).

\section{Control (cerebral venous thrombosis- negative)}

The backward-selection multiple linear regression on the control group data $(n=59)$ showed that of all the above-mentioned variables (symptom types excluded), only age (beta=0.303; $\mathrm{P}=0.018$ ) and female gender (beta $=0.293 ; \mathrm{P}=0.022$ ) positively predicted $\mathrm{D}$ dimer levels in the controls, and all other variables were insignificant. None of the symptoms was associated with D-dimer levels in the control group.

\section{Analysis of complete data}

Based on the t-test results, the difference between the D-dimer level of the case and control groups was significant $(\mathrm{P}<0.001)$. A regression analysis was performed over the whole data $(n=88)$. The variables included all the items in above-mentioned regressions as well as the number of symptoms present in patients, but excluding the types of symptoms. Only age (beta $=0.086 ; \mathrm{P}=0.022$ ) and thrombosis (beta $=0.940 ; \mathrm{P}=0.000000$ ) were predictors of D-dimer levels. A separate analysis was performed on symptom types only. According to the linear regression, all symptom types except headache were positively associated with D-dimer levels, while headache was negatively associated with Ddimer levels (Table 1). Spearman's coefficient showed excellent correlations between thrombosis occurrence, D-dimer levels, and symptoms (Table 2). The multiple binary logistic regression analysis was used to assess the association of all variables except D-dimer and symptom types with thrombosis occurrence. It showed that each level of increase in the number of symptoms could increase the risk of thrombosis occurrence for about 3.5 times [odds ratio $(\mathrm{OR})=3.4$, Table 3].

\section{D-dimer's cut-off value for cere-} bral venous thrombosis prediction

The rounded critical D-dimer cut-off point was estimated to be $350 \mathrm{ng} / \mathrm{mg}$ (rounded from $342.5 \mathrm{ng} / \mathrm{mg}$ ), above which, patients are at a much increased risk of thrombosis (receiveroperator curve's $\mathrm{P}<0.0001$ ).

\section{Discussion}

D-dimer increases in the serum following fibrinolysis of blood clots. ${ }^{10}$ Assessment of its serum levels can confirm the process of clot formation and fibrinolysis. Based on our results the serum level of D-dimer was significantly higher in CVT patients than in the control group. Furthermore, all the CVT signs were associated with the D-dimer level, except for headache. An increase in the number of symptoms was associated with an increased risk of thrombosis. Age and the female gender were positively associated with the D-dimer level.

The D-dimer level was significantly different in the CVT group when compared to the control group in $350 \mathrm{ng} / \mathrm{mg}$ cut-off level. Other studies have confirmed elevated levels of serum D-dimer following CVT, but critical cut-off value was $500 \mathrm{ng} / \mathrm{mg}$ in most studies, ${ }^{11,12}$ probably due to the prevalence of other CVT predisposing factors in different populations. Lalive and colleagues assessed the D-dimer level for the purpose of CVT diagnosis, and found the sensitivity and specificity to be $83 \%$ and $90 \% .13$ Dentali and colleagues studied the diagnostic value of Ddimer serum level in CVT. The weighted mean sensitivity of D-dimer was estimated at 93.9\% (95\% CI 87.5-97.1) and its weighted mean specificity was estimated at $89.7 \%$ (95\% CI 86.5-92.2). ${ }^{14}$ So, it seems that decreasing D-dimer cut-off level may increase the diagnostic value of this test in CVT. In this study, the female gender and age were D-dimer level determinants in patients

Table 1. Linear regression test of D-dimer serum level in patients with and without cerebral venous thrombosis.

\begin{tabular}{lccc} 
Symptom & Beta & $\mathrm{t}$ & $\mathrm{P}$ \\
Headache & -0.452 & -4.622 & 0.000 \\
Hemiparesis & 0.251 & 2.772 & 0.007 \\
\hline Seizure & 0.205 & 2.758 & 0.007 \\
Other symptoms & 0.260 & 3.639 & 0.000 \\
\hline
\end{tabular}


Table 2. Spearman correlation coefficient test of D-dimer serum level in patients with and without cerebral venous thrombosis.

\begin{tabular}{|c|c|c|c|c|c|c|c|c|c|c|c|c|c|}
\hline & & $\begin{array}{l}\text { Sex Age } \\
\text { dimer }\end{array}$ & $\begin{array}{c}\text { D- } \\
\text { number }\end{array}$ & Symptom & Headache & Hemiparesis & $\begin{array}{l}\text { s Seizure } \\
\text { symptoms }\end{array}$ & Other & $\begin{array}{c}\text { Smoking } \\
\text { contraceptive } \\
\text { use }\end{array}$ & $\begin{array}{l}\text { Oral } \\
\text { mass } \\
\text { index }\end{array}$ & Menopause & Pregnancy & Body \\
\hline Age & $\begin{array}{l}\text { Rho } \\
\text { P }\end{array}$ & $\begin{array}{l}0.207 \\
0.053\end{array}$ & & & & & & & & & & & \\
\hline D-dimer & $\begin{array}{l}\text { Rho } \\
\text { P }\end{array}$ & $\begin{array}{rr}-0.117 & 0.125 \\
0.278 & 0.246\end{array}$ & & & & & & & & & & & \\
\hline Symptom number & $\begin{array}{l}\text { Rho } \\
\text { P }\end{array}$ & $\begin{array}{cc}-0.069 & -0.038 \\
0.524 & 0.724\end{array}$ & $\begin{array}{l}0.266 \\
0.012\end{array}$ & & & & & & & & & & \\
\hline Headache & $\begin{array}{l}\text { Rho } \\
\text { P }\end{array}$ & $\begin{array}{cc}-0.019 & -0.266 \\
0.862 & 0.012\end{array}$ & $\begin{array}{c}-0.586 \\
0.000\end{array}$ & $\begin{array}{l}0.021 \\
0.850\end{array}$ & & & & & & & & & \\
\hline Hemiparesis & $\begin{array}{l}\text { Rho } \\
\text { P }\end{array}$ & $\begin{array}{ll}0.029 & 0.211 \\
0.788 & 0.048\end{array}$ & $\begin{array}{l}0.399 \\
0.000\end{array}$ & $\begin{array}{l}0.061 \\
0.575\end{array}$ & $\begin{array}{l}-0.592 \\
0.000\end{array}$ & & & & & & & & \\
\hline Seizure & $\begin{array}{l}\text { Rho } \\
\text { P }\end{array}$ & $\begin{array}{rr}-0.040 & 0.045 \\
0.715 & 0.679\end{array}$ & $\begin{array}{l}0.354 \\
0.001\end{array}$ & $\begin{array}{l}0.776 \\
0.000\end{array}$ & $\begin{array}{l}-0.325 \\
0.002\end{array}$ & $\begin{array}{l}-0.054 \\
0.620\end{array}$ & & & & & & & \\
\hline Other symptoms & $\begin{array}{l}\text { Rho } \\
\text { P }\end{array}$ & $\begin{array}{ll}-0.094 & -0.005 \\
0.385 & 0.964\end{array}$ & $\begin{array}{l}0.307 \\
0.004\end{array}$ & $\begin{array}{l}0.332 \\
0.002\end{array}$ & $\begin{array}{l}-0.248 \\
0.020\end{array}$ & $\begin{array}{l}-0.059 \\
0.582\end{array}$ & $\begin{array}{l}0.135 \\
0.211\end{array}$ & & & & & & \\
\hline Smoking & $\begin{array}{l}\text { Rho } \\
\text { P }\end{array}$ & $\begin{array}{ll}0.428 & 0.415 \\
0.000 & 0.000\end{array}$ & $\begin{array}{l}0.068 \\
0.527\end{array}$ & $\begin{array}{l}-0.112 \\
0.297\end{array}$ & $\begin{array}{l}-0.054 \\
0.617\end{array}$ & $\begin{array}{l}-0.074 \\
0.493\end{array}$ & $\begin{array}{l}-0.070 \\
0.519\end{array}$ & $\begin{array}{l}0.084 \\
0.436\end{array}$ & & & & & \\
\hline Oral contraceptive use & $\begin{array}{l}\text { Rho } \\
\text { P }\end{array}$ & $\begin{array}{ll}0.969 & 0.260 \\
0.000 & 0.173\end{array}$ & $\begin{array}{l}0.188 \\
0.327\end{array}$ & $\begin{array}{l}-0.018 \\
0.928\end{array}$ & $\begin{array}{l}-0.074 \\
0.702\end{array}$ & $\begin{array}{l}0.041 \\
0.831\end{array}$ & $\begin{array}{l}0.108 \\
0.576\end{array}$ & $\begin{array}{l}-0.190 \\
0.323\end{array}$ & $\begin{array}{l}0.443 \\
0.016\end{array}$ & & & & \\
\hline Menopause & $\begin{array}{l}\text { Rho } \\
\text { P }\end{array}$ & $\begin{array}{rr}-0.744 & -0.522 \\
0.000 & 0.004\end{array}$ & $\begin{array}{l}-0.281 \\
0.140\end{array}$ & $\begin{array}{l}-0.026 \\
0.895\end{array}$ & $\begin{array}{l}0.247 \\
0.197\end{array}$ & $\begin{array}{l}-0.414 \\
0.026\end{array}$ & $\begin{array}{l}0.110 \\
0.571\end{array}$ & $\begin{array}{l}0.017 \\
0.931\end{array}$ & $\begin{array}{l}-0.340 \\
0.071\end{array}$ & $\begin{array}{l}-0.661 \\
0.000\end{array}$ & & & \\
\hline Pregnancy & $\begin{array}{l}\text { Rho } \\
\text { P }\end{array}$ & $\begin{array}{cc}-0.288 & -0.218 \\
0.006 & 0.042\end{array}$ & $\begin{array}{l}0.148 \\
0.169\end{array}$ & $\begin{array}{l}0.060 \\
0.576\end{array}$ & $\begin{array}{l}-0.019 \\
0.858\end{array}$ & $\begin{array}{l}-0.078 \\
0.472\end{array}$ & $\begin{array}{l}0.141 \\
0.189\end{array}$ & $\begin{array}{c}-0.046 \\
0.670\end{array}$ & $\begin{array}{l}-0.123 \\
0.252\end{array}$ & $\begin{array}{l}-0.434 \\
0.019\end{array}$ & $\begin{array}{l}0.506 \\
0.005\end{array}$ & . & \\
\hline Body mass index & $\begin{array}{l}\text { Rho } \\
\text { P }\end{array}$ & $\begin{array}{cc}-0.038 & 0.262 \\
0.725 & 0.014\end{array}$ & $\begin{array}{l}0.121 \\
0.260\end{array}$ & $\begin{array}{l}-0.051 \\
0.639\end{array}$ & $\begin{array}{l}-0.219 \\
0.040\end{array}$ & $\begin{array}{l}0.156 \\
0.147\end{array}$ & $\begin{array}{l}0.050 \\
0.644\end{array}$ & $\begin{array}{l}-0.051 \\
0.640\end{array}$ & $\begin{array}{l}0.129 \\
0.230\end{array}$ & $\begin{array}{l}-0.122 \\
0.528\end{array}$ & $\begin{array}{l}-0.080 \\
0.678\end{array}$ & $\begin{array}{l}0.245 \\
0.022\end{array}$ & \\
\hline Thrombosis & $\begin{array}{l}\text { Rho } \\
\text { P }\end{array}$ & $\begin{array}{cc}-0.040 & -0.023 \\
0.715 & 0.829\end{array}$ & $\begin{array}{l}0.815 \\
0.000\end{array}$ & $\begin{array}{l}0.262 \\
0.014\end{array}$ & $\begin{array}{l}-0.647 \\
0.000\end{array}$ & $\begin{array}{l}0.451 \\
0.000\end{array}$ & $\begin{array}{l}0.383 \\
0.000\end{array}$ & $\begin{array}{l}0.268 \\
0.012\end{array}$ & $\begin{array}{l}0.000 \\
0.995\end{array}$ & & & $\begin{array}{l}0.141 \\
0.189\end{array}$ & $\begin{array}{l}0.084 \\
0.437\end{array}$ \\
\hline Factor V Leiden & $\begin{array}{l}\text { Rho } \\
\text { P }\end{array}$ & $\begin{array}{ll}0.159 & -0.323 \\
0.409 & 0.087\end{array}$ & $\begin{array}{l}0.000 \\
1.000\end{array}$ & $\begin{array}{l}0.219 \\
0.254\end{array}$ & $\begin{array}{l}0.014 \\
0.943\end{array}$ & $\begin{array}{l}-0.023 \\
0.905\end{array}$ & $\begin{array}{l}0.133 \\
0.491\end{array}$ & $\begin{array}{l}0.192 \\
0.317\end{array}$ & $\begin{array}{l}-0.203 \\
0.292\end{array}$ & $\begin{array}{l}0.134 \\
0.487\end{array}$ & $\begin{array}{l}-0.052 \\
0.788\end{array}$ & $\begin{array}{l}-0.136 \\
0.482\end{array}$ & $\begin{array}{r}-0.282 \\
0.139\end{array}$ \\
\hline
\end{tabular}

clear of CVT, while age alone might predict Ddimer levels among CVT patients (and in the whole sample of both CVT patients and those without CVT). Other studies showed that, in middle-aged women CVT was three times more common among women than in men. ${ }^{3}$ This difference is due to the difference in risk factors (such as 0CPs, pregnancy, menopausal age, hormone replacement therapy). 15 One fourth of the female population of this sample took contraceptives, and about the same number were menopausal. Studies have also shown that the incidence of CVT at older age is associated with the presentation of more severe and fewer minor symptoms; more often it presents with decreased consciousness. Previously, it has been recognized that the D-dimer level is directly associated with the size of the thrombus. It appears that older age is associated with an increased size of thrombus, which in turn creates more severe symptoms and elevates the D-dimer level. ${ }^{8}$ Moreover, morphological changes (cortical atrophy, hippocampus, and subcortical tissue changes) and biochemical changes of the brain (reduced cholinergic and dopaminergic activity) are associated with increase in age. ${ }^{16}$ Simultaneously, agerelated changes in cerebral blood flow make the brain tissue more vulnerable, ${ }^{16}$ leading to

Table 3. Binary logistic regression test of factors associated with cerebral venous thrombosis.

\begin{tabular}{lccc} 
Variable & P & OR & $95 \%$ CI for OR \\
Male sex & 0.859 & 0.908 & $0.314,2.632$ \\
Age & 0.491 & 0.987 & $0.950,1.025$ \\
\hline Number of symptoms & 0.012 & 3.399 & $1.305,8.849$ \\
Smoking & 0.678 & 1.346 & $0.331,5.478$ \\
\hline Body mass index & 0.219 & 1.157 & $0.917,1.460$ \\
\hline
\end{tabular}

$\mathrm{OR}$, odds ratio; $\mathrm{Cl}$, confidence interval.

more severe symptoms and CVT complications compared to younger CVT.

Usually, the absence of headache in CVT indicates parenchymal damages and more severe symptoms such as seizures and motor weakness. ${ }^{17}$ A previous study showed that Ddimers have a high negative predictive value in patients with isolated headache for excluding CVT,18 in our study, apart from headache, all the symptoms were associated with a rise in D-dimer level. This lack of association may perhaps be attributed to the size of the thrombus in CVT, which results in all the symptoms but headache. However, further more controlled studies are needed to evaluate this.

\section{Conclusions}

CVT may occur more in patients with a higher number of symptoms. No strong association was found between CVT risk and items such as age, smoking, or BMI. D-dimer level may be higher in older patients and those experiencing either hemiparesis, seizure, or a combination of confusion, ataxia, and visual problems, but not in those with headache (which showed a negative association and needs future research). D-dimer serum level significantly rises in CVT patients compared to the control group. A rounded cut-off point of $350 \mathrm{ng} / \mathrm{mg}$ can be used as a diagnostic criterion for CVT prediction. 
et al. A comparison of three rapid D-dimer methods for the diagnosis of venous thromboembolism. $\mathrm{Br} \mathrm{J}$ Haematol 2001;115:140-4.

1. Bousser MG. Cerebral venous thrombosis: diagnosis and management. J Neurol 2000;247:252-8.

2. Ageno W, Dentali F, Squizzato A, et al. Evidence and clinical judgment: treatment of cerebral vein thrombosis. Thromb Haemost 2010;103:1109-15.

3. Ferro JM, Canhao P, Stam J, et al. Prognosis of cerebral vein and dural sinus thrombosis: results of the International Study on Cerebral Vein and Dural Sinus Thrombosis (ISCVT). Stroke 2004;35:66470.

4. Dentali F, Gianni M, Crowther MA, Ageno W. Natural history of cerebral vein thrombosis: a systematic review. Blood 2006;108:1129-34.

5. Linn J, Brückmann H. Cerebral venous and dural sinus thrombosis: state-of-theart imaging. Clin Neuroradiol 2010;20:2537.

6. Kovacs MJ, MacKinnon KM, Anderson D,
7 Bates SM, Grand'Maison A, Johnston M, et al. A latex D-dimer reliably excludes venous thromboembolism. Arch Intern Med 2001;161:447-53.

8. Gouda T, Sabry HM. Evaluation of plasma D-dimer assay as a diagnostic biomarker for cerebral venous thrombosis. Egypt J Neurol Psychiatry Neurosurg 2010;47:3316.

9. Misra UK, Kalita J, Bansal V. D-dimer is useful in the diagnosis of cortical venous sinus thrombosis. Neurol India 2009;57:50-4.

10. Haapaniemi E, Tatlisumak T. Is D-dimer helpful in evaluating stroke patients? A systematic review. Acta Neurol Scand 2009;119:141-50.

11. Tardy B, Tardy-Poncet B, Viallon A, et al. Ddimer levels in patients with suspected acute cerebral venous thrombosis. Am J Med 2002;113:238-41.

12. Wildberger JE, Mull M, Kilbinger M, et al.
[Cerebral sinus thrombosis: rapid test diagnosis by demonstration of increased plasma D-dimer levels (SimpliRED)]. Rofo 1997;167:527-9. [Article in German]

13. Lalive PH, De Moerloose P, Lovblad K, et al. Is measurement of D-dimer useful in the diagnosis of cerebral venous thrombosis? Neurology 2003;61:1057-60.

14. Dentali F, Squizzato A, Marchesi C, et al. D-dimer testing in the diagnosis of cerebral vein thrombosis: a systematic review and a meta-analysis of the literature. J Thromb Haemost 2012;10:582-9.

15. Stam J. Thrombosis of the cerebral veins and sinuses. N Engl J Med 2005;352:1791-8.

16. Choi JY, Morris JC, Hsu CY. Aging and cerebrovascular disease. Neurol Clin 1998;16:687-711.

17. Bousser MG, Ferro JM. Cerebral venous thrombosis: an update. Lancet Neurol 2007;6:162-70.

18. Alons IM, Jellema K, Wermer MJ, Algra A. D-dimer for the exclusion of cerebral venous thrombosis: a meta-analysis of low risk patients with isolated headache. BMC Neurol 2015;15:118. 